\title{
Changes of PVC Nanocomposite Properties CONNECTED With Clay CONTENT
}

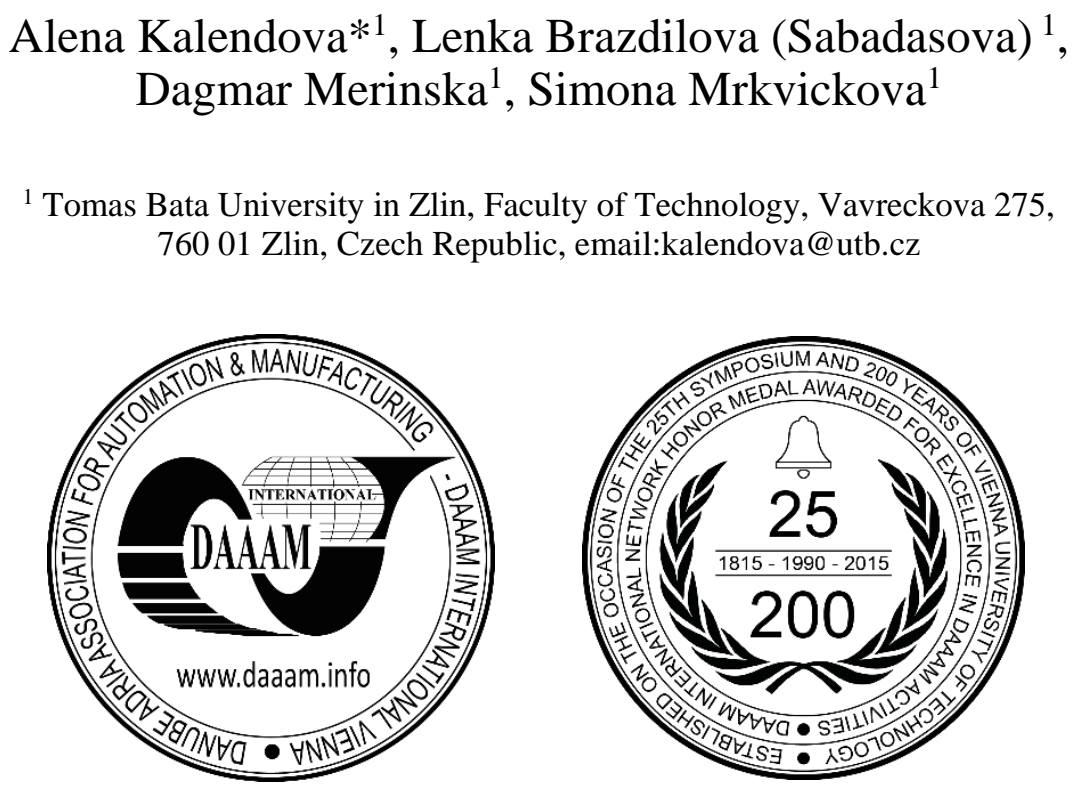

This Publication has to be referred as: Kalendova, A[lena]; Brazdilova Sabadasova, L[enka]; Merinska, D[agmar] \& Mrkvickova, S[imona] (2017). Changes of PVC Nanocomposite Properties Connected with Clay Content, Proceedings of the 28th DAAAM International Symposium, pp.0921-0925, B. Katalinic (Ed.), Published by DAAAM International, ISBN 978-3-902734-11-2, ISSN 1726-9679, Vienna, Austria

DOI: $10.2507 / 28$ th.daaam.proceedings. 127

\begin{abstract}
The polyvinylchloride $(P V C)$ is an extensively used thermoplastic material, therefore the research were focused on this polymer. The aim of this work was to determinate the current development of nanocomposite materials based the polyvinylchloride and the influence of filler loading on their thermal and electrical properties. As nanofillers were used clays derived from montmorillonite (MMT): MMTNa+ and MMT30B. MMTNa+ presented sodium type of montmorillonite and MMT30 is organically modified type of MMT. Both of the clays were intercalated or cointercalated with plasticizer bis(2-ethylhexyl) phthalate (DEHP). As the compounder the Buss KO-kneader was selected. This type of compounder is suitable for processing temperature-sensitive polymers. The properties as thermal and electrical conductivity were evaluated in comparison to the structure.
\end{abstract}

Keywords: PVC; nanocomposite; clay; conductivity

\section{Introduction}

Among all types of plastics, polyvinyl chloride (PVC) is one of the most important but also potential environmentally hazardous polymer materials for the content of chlorine [1] and large amount of processing additives. But it is still the world's third-most widely produced synthetic polymer after polyethylene and polypropylene. The reason for its huge utilization derivate from this facts: low flammability, high chemical resistance, barrier properties, low cost, and formulating versatility. Next PVC is one of the typical insulating materials, and electric charges can be easily generated and accumulated on PVC surfaces, resulting in static-electric spark and even fire disasters [2]. In some circumstances such as chemical plants, gas stations, and coal mines, anti-static properties of PVC products are extremely important for ensurance of safety and reliability [3]. In that case, developing anti-static PVC materials has aroused much attention from academic and industrial fields for several decades. 
Next, there has been a rapid development of solid-phase polymeric nanocomposites over the past 20 years. In particular, organically modified montmorillonites have been widely studied from fundamental and practical points of view in the area of organic-inorganic hybrid nanocomposites [4-10]. The structure of polymer-clay mineral nanocomposites mostly depends on the thermodynamic compatibility between the polymer, clay mineral and organic modifier.

Montmorillonite (MMT) is an aluminosilicate type of smectite clay mineral having a 2:1 expanding crystal lattice. Its crystalline structure is composed of an alumina octahedral sheet between two tetrahedral sheets of silica. Montmorillonite (MMT) s usually organically modified by ion-exchange reactions with primary, secondary, tertiary and quaternary alkylammonium or alkylphosphonium salts [11]. These types of MMT have, when exfoliated, a number of improved properties including mechanical strength, barrier properties, flammability resistance, electrical/electronic properties and polymer blend compatibilization with most polymer matrices [12,13].

The aim of this work was established the influence of filler content on the polymer composite properties especially thermal and electrical conductivity in correlation to the structure of material.

\section{Material and methods}

\subsection{Materials}

The polymer matrix was presented by the suspension type of PVC (Neralit 652, $K=65$ ). Two types of montmorillonite, $M M T 30 B$ and $M M T N a+$, from Southern Clay Products, were used as the nanofillers. MMTNa+ represents a sodium montmorillonite $(\mathrm{d}$-spacing $=1.2 \mathrm{~nm})$ with no organic surface treatment. MMT30B contains methyl tallow bis-2-hydroxyethyl ammonium cation at a loading of $90 \mathrm{meq} / 100 \mathrm{~g}$, $(\mathrm{d}$-spacing $=1.8 \mathrm{~nm})$. The level of loading varied from $0.5,1,3,5,10,15$ and $20 \%$. Plasticizer bis(2-ethylhexyl) phthalate (DEHP) plays role of intercalant or cointercalant. As the compounder the Buss KO-kneader MKS 30 was selected. This single-screw compounder is suitable for processing temperature-sensitive polymers. The barrel diameter was $30 \mathrm{~mm}$ and speed $50 \mathrm{rpm}$. The operating temperature changed from $130{ }^{\circ} \mathrm{C}$ at the entrance zone to $160{ }^{\circ} \mathrm{C}$ in the exit zone. After the pelletization of obtained strings the pellets were pressed into $1 \mathrm{~mm}$ sheets. The changes from $20-36 \%$ in case of thermal conductivity and more than $400 \%$ for el. conductivity were observed.

\subsection{Experimental methods}

Thermal conductivity is a property of the environment and depends generally on the temperature, pressure, composition of the system and also on the density of the substance being investigated. Its values greatly depend on the type of material and its state. For this study was employed non-stationary heat conduction measurement based on Fitche instrument [14]. This measurement has many advantages including, in particular, the short measurement time, the simplicity of the process and the measuring device, as well as the possibility of determining the important influence of the moisture content of the insulating material samples on their thermal conductivity. Measurements were performed from $45^{\circ} \mathrm{C}$ to $25^{\circ} \mathrm{C}$. Software LabView Signal Express was used for data collection. Tested samples have dimension $40 x 40 x 1$ $\mathrm{mm}$.

The electric conductivity were measured using a two-point method with a Keithley 6517A programmable electrometer, which at the same time served as a source of the DC voltage. The range of the measured voltage was 0 $100 \mathrm{~V}$. Based on these measurements, it was calculated the specific electrical conductivity according to the equation (1):

$$
\sigma=\frac{I}{U} * \frac{l}{S}
$$

where U-voltage (V), I-current (A), S-electrode area $\left(\mathrm{cm}^{2}\right), 1$-sample thickness $(\mathrm{cm}), \sigma$-electric. conductivity $\left(\mathrm{S} / \mathrm{cm}^{-1}\right)$.

Further the structure was monitored using X-ray diffraction (PAN analytical X'Pert PRO with a cathode CuK $\alpha$ in a reflective arrangement from angles $2 \Theta: 1-30^{\circ}$ and SEM (SEM Vega Tescan). Samples were placed in liquid nitrogen and afterwards freeze-fractured.

\section{Results}

With the low-cost polymer as a matrix material, the composite can often be formed into products with higher thermal conductivity than the original polymer. In this study, the thermal conductivity was measured by a non-stationary method on a type of Fitche device. The average values of thermal conductivity of prepared samples are given in Table 1,2 and Fig. 1. The thermal conductivity is growing with filler loading for both filler. The bigger influence was recorded for $M M T N a+$. The increase 24\% was observed for loading 3 and $5 \% M M T N a+$. The improvement $36 \%$ show sample with $20 \%$ of natural MMT. The mixture $M M T 30 B$ show lower conductivity growth comparing $M M T N a+$. The increase was 9 and $19 \%$ for mixture $P V C / 3 \% M M T 30 B$ and $P V C / 5 \% M M T 30$. The highest change of $25 \%$ was recorded for $P V C / 20 \% M M T 30 B$. The lower changes by lower filler loading may be connected with the morphology of sample. The 
mixtures with loading to $5 \%$ show very fine structure. The filler is well dispersed in the matrix with the particles in nm range. In case of higher loading the morphology study show the mixture of nanoparticles and microparticles as can be seen in Fig. 2.

Next the DC electrical conductivity was measured. The values, obtained from the measurements, are shown in the Table 3, 4. There can be no free charge carriers in pure PVC, therefore we consider the polyvinyl chloride matrix as an insulator. The significant increase was observed in case $M M T / 15 \% 30 B$ and $M M T / 20 \% 30 B$ (more than $400 \%$ ). The $M M T N a+$ cause the drop of electrical conductivity comparing pure PVC. This facts are in good correlation with the morphology of tested samples. $M M T 3 O B$ is modified clay and this modifier may create the charge carrier. Next the MMT30B created, due to the good dispersion of filler in matrix a "filler network, which can be helped to lead the el. charge. In case of $M M T N a+$ the microparticles are separated (isolated) in polymer matrix, which is dielectric.

\begin{tabular}{|c|c|c|}
\hline Sample & $\begin{array}{c}\boldsymbol{\lambda} \\
\left(\mathbf{W} \cdot \mathbf{m}^{-\mathbf{1}} \cdot \mathbf{K}^{-\mathbf{1}}\right)\end{array}$ & $\begin{array}{c}\Delta \boldsymbol{\lambda} \\
\left(\mathbf{W} \cdot \mathbf{m}^{-\mathbf{1}} \cdot \mathbf{K}^{\mathbf{- 1}}\right)\end{array}$ \\
\hline Pure PVC & 0.127 & 0.002 \\
\hline PVC/0.5 MMT Na+ & 0.129 & 0.001 \\
\hline PVC/1 MMT Na+ & 0.135 & 0.001 \\
\hline PVC/3 MMT Na+ & 0.157 & 0.001 \\
\hline PVC/5 MMT Na+ & 0.158 & 0.001 \\
\hline PVC/10 MMT Na+ & 0.168 & 0.002 \\
\hline PVC/15 MMT Na+ & 0.172 & 0.002 \\
\hline PVC/20 MMT Na+ & 0.163 & 0.002 \\
\hline
\end{tabular}

Table 1 Thermal conductivity MMTNa+

\begin{tabular}{|c|c|c|}
\hline Sample & $\begin{array}{c}\boldsymbol{\lambda} \\
\left(\mathbf{W} \cdot \mathbf{m}^{-\mathbf{1}} \cdot \mathbf{K}^{-\mathbf{1}}\right)\end{array}$ & $\begin{array}{c}\Delta \boldsymbol{\lambda} \\
\left(\mathbf{W} \cdot \mathbf{m}^{-\mathbf{1}} \cdot \mathbf{K}^{-\mathbf{1}}\right)\end{array}$ \\
\hline Pure PVC & 0.127 & 0.002 \\
\hline PVC/0.5 MMT30B & 0.128 & 0.001 \\
\hline PVC/1 MMT30B & 0.136 & 0.001 \\
\hline PVC/3 MMT30B & 0.139 & 0.002 \\
\hline PVC/5 MMT30B & 0.151 & 0.001 \\
\hline PVC/10 MMT30B & 0.152 & 0.001 \\
\hline PVC/15 MMT30B & 0.158 & 0.001 \\
\hline PVC/20 MMT30B & 0.159 & 0.001 \\
\hline
\end{tabular}

Table 2 Thermal conductivity $M M T 30 B$

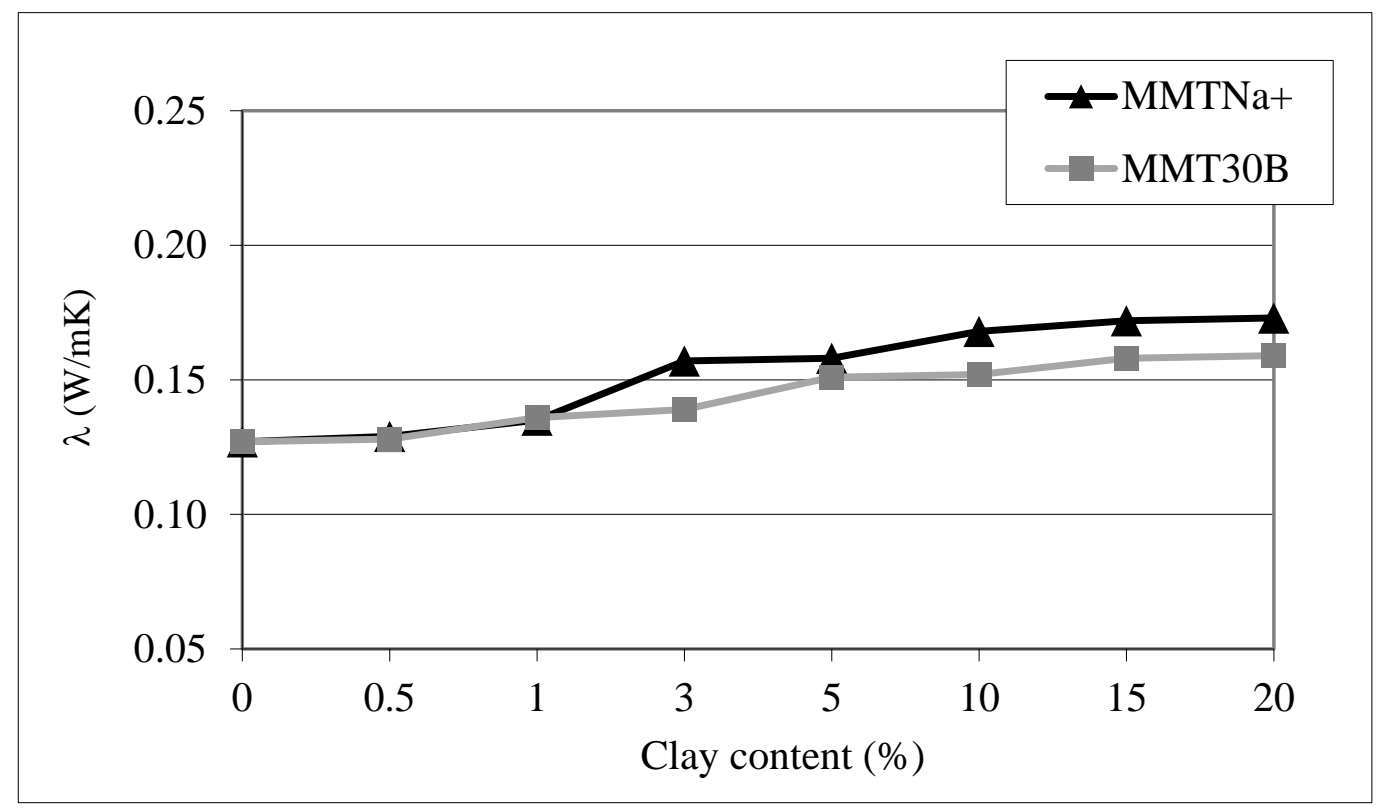

Fig.1. Thermal conductivity 


\begin{tabular}{|c|c|c|}
\hline Sample & $\begin{array}{c}\sigma \\
\left(\mathrm{S} / \mathrm{cm}^{-1} * 10^{-13}\right) \\
\text { for } U=80 \mathrm{~V}\end{array}$ & $\begin{array}{c}\Delta \sigma \\
\left(\mathrm{S} / \mathrm{cm}^{-1} * 10^{-14}\right) \\
\text { for } \mathrm{U}=\mathbf{8 0 \mathrm { V }}\end{array}$ \\
\hline Pure PVC & 2.48 & 2.01 \\
\hline PVC/0.5 MMT Na+ & 3.47 & 2.48 \\
\hline $\mathrm{PVC} / 1 \mathrm{MMT} \mathrm{Na}+$ & 2.01 & 1.00 \\
\hline $\mathrm{PVC} / 3 \mathrm{MMT} \mathrm{Na}+$ & 1.80 & 1.27 \\
\hline $\mathrm{PVC} / 5 \mathrm{MMT} \mathrm{Na}+$ & 2.24 & 1.37 \\
\hline PVC/10 MMT Na+ & 2.52 & 1.32 \\
\hline PVC/15 MMT Na+ & 2.15 & 1.99 \\
\hline $\mathrm{PVC} / 20 \mathrm{MMT} \mathrm{Na}+$ & 1.85 & 1.15 \\
\hline
\end{tabular}

Table 3 DC Electrical conductivity for samples with MMTNa+

\begin{tabular}{|c|c|c|}
\hline Sample & $\begin{array}{c}\sigma \\
\left(\mathrm{S} / \mathrm{cm}^{-1 * 10^{-13}}\right) \\
\text { for } \mathrm{U}=\mathbf{8 0 V} \\
\end{array}$ & $\begin{array}{c}\Delta \sigma \\
\left(\mathrm{S} / \mathbf{c m}^{-1 * 10^{-14}}\right) \\
\text { for } \mathrm{U}=\mathbf{8 0 V} \\
\end{array}$ \\
\hline Pure PVC & 2.48 & 2.01 \\
\hline PVC/0.5 MMT30B & 5.05 & 2.30 \\
\hline PVC/1 MMT30B & 6.38 & 1.94 \\
\hline PVC/3 MMT30B & 3.75 & 1.83 \\
\hline $\mathrm{PVC} / 5$ MMT30B & 5.25 & 0.51 \\
\hline PVC/10 MMT30B & 6.83 & 0.45 \\
\hline PVC/15 MMT30B & 12.17 & 2.27 \\
\hline PVC/20 MMT30B & 17.90 & 1.98 \\
\hline
\end{tabular}

Table 4 DC Electrical conductivity for samples with $M M T 30 B$
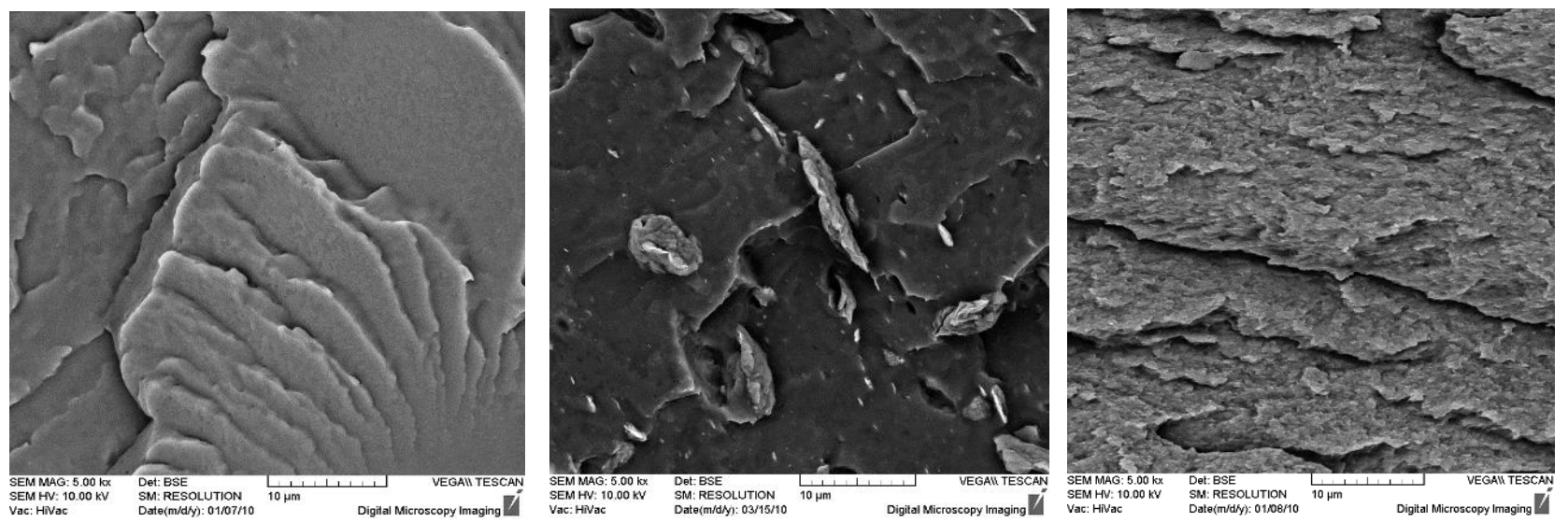

Fig. 2. SEM: Pure PVC, PVC/10\% MMTNa+, PVC/10\% MMT30B (from left)

\section{Conclusion}

The polyvinylchloride (PVC) is an extensively used thermoplastic material, therefore the research were focused on this polymer. Next developing anti-static PVC materials has aroused much attention from academic and industrial fields. The aim of this work was to determinate the influence of filler loading to the thermal and electrical conductivity in correlation to the structure of prepared mixtures. In accordance with the obtained results, the thermal conductivity is growing with filler loading for both filler.

The bigger influence was recorded for $M M T N a+$, where improvement $36 \%$ for $20 \%$ loading was observed. While, it was only $25 \%$ for $20 \%$ loading of $M M T 30 B$. This fact may be connected with the morphology of the sample. The filler $M M T 30 B$ seems to be well dispersed in the matrix and it is restricted the polymer chain motion. This may create a barrier for thermal conduction.

In case of DC el. conductivity, the significant increase was observe for $M M T / 15 \% 30 B$ and $M M T / 20 \% 30 B$ (more than $400 \%)$. This fact is probably connected with the filler modification which may create the charge carriers in the filler surface and the "filler network" in polymer matrix. The future plan is testing other types of intercalated or cointercalated fillers especially for el. conductivity. 


\section{Acknowledgments}

This project was supported by internal grant of TBU in Zlin RVOE. Next I wish to thanks Mr. Antonin Blaha for the help with the thermal conductivity measurement.

\section{References}

[1] Han Wang; Guiyuan Xie; Minghe Fang; Zhe Ying; Yu Tong; You Zeng, (2015). Electrical and mechanical properties of antistatic PVC films containing multi-layer graphene. Composites Part B. 79. 444-450.

[2] Saad ALG; Sayed WM; Ahmed MGM; Hassan AM. (1999). Preparation and properties of some filled poly(vinyl chloride) compositions. J Appl Polym Sci. 73(13). 2657-70.

[3] Moulay S. (2010). Chemical modification of poly(vinyl chloride)- still on the run. ProgPolym Sci. 35(3). 303-31.

[4] Giannelis E.P. (1996). Polymer layered silicate nanocomposites. Adv. Mater. 8. 29-35.

[5] Alexandre M.; Dubois P. (2000). Polymer-layered silicate nanocomposites: preparation, properties and uses of a new class of materials. Mater. Sci. Eng. R. Rep. 28. 1-63.

[6] Fornes T.D.; Yoon P.J.; Hunter D.L.; Keskkula H.; Paul D.R. (2002). Effect of organoclay structure on nylon 6 nanocomposite morphology and properties. Polymer. 43. 5915-5933.

[7] Stretz H.A.; Paul D.R.; Li R.; Keskkula H.; Cassidy P.E. (2005). Intercalation and exfoliation relationships in meltprocessed poly(styrene-co-acrylonitrile)/montmorillonite nanocomposites. Polymer. 46. 2621-2637.

[8] Peprnicek T.; Kalendova A.; Pavlova E.; Simonik J.; Duchet J.; Gerard J.F. (2006). Poly(vinyl chloride)-paste/clay nanocomposites: investigation of thermal and morphological characteristics. Polym. Degrad. Stab. 91. 3322-3329.

[9] Shah R.K.; Kim D.H.; Paul D.R. (2007). Morphology and properties of nanocomposites formed from ethylene/methacrylic acid copolymers and organoclays. Polymer. 48. 1047-1057.

[10] Merinska D.; Kubisova H.; Kalendova A.; Svoboda P.; Hromadkova J. (2012). Processing and properties of polyethylene/montmorillonite nanocomposites. Journal of Thermplastic Composite Materials. 25(1). 115-131.

[11] McAtee J.J. (1956). Heterogeneity in montmorillonite. Clay Minerals. 5. 279-288.

[12] Paul D.R.; Robeson L.M. (2008). Polymer nanotechnology: nanocomposites. Polymer. 49. 3187-3204.

[13] Petersen H.; Jakubowicz I.; Enebro J.; Yarahmadi J. (2015) Organic modification of montmorillonite for application in plasticized PVC nanocomposites. Applied Clay Science. 107. 78-84

[14] Blaha A.; Pavlica. R. Thermal conductivity measurement by non-stationary method. Mereni tepelne vodivosti nestacionarni metodou. (2001). CHISA.15. - 18. ř́jna 2001. Srni. Sumava. Czech Republic. Czech Society of Chemical Engineering . ISBN 80-86059-32-4. 